\title{
Mechanical, Structural, and Biological Properties of Chitosan/Hydroxyapatite/Silica Composites for Bone Tissue Engineering
}

\author{
Robert Adamski and Dorota Siuta *(D)
}

check for updates

Citation: Adamski, R.; Siuta, D.

Mechanical, Structural, and Biological Properties of Chitosan/

Hydroxyapatite/Silica Composites

for Bone Tissue Engineering.

Molecules 2021, 26, 1976. https://

doi.org/10.3390/molecules26071976

Academic Editor: Katarína Valachová

Received: 9 March 2021

Accepted: 28 March 2021

Published: 31 March 2021

Publisher's Note: MDPI stays neutral with regard to jurisdictional claims in published maps and institutional affiliations.

Copyright: (c) 2021 by the authors. Licensee MDPI, Basel, Switzerland. This article is an open access article distributed under the terms and conditions of the Creative Commons Attribution (CC BY) license (https:/ / creativecommons.org/licenses/by/ $4.0 /)$.
Faculty of Process and Environmental Engineering, Lodz University of Technology, 90-924 Lodz, Poland; robert.adamski@p.lodz.pl

* Correspondence: dorota.siuta@p.lodz.pl; Tel.: +48-42631-3744

\begin{abstract}
The aim of this work was to fabricate novel bioactive composites based on chitosan and non-organic silica, reinforced with calcium $\beta$-glycerophosphate (Ca-GP), sodium $\beta$-glycerophosphate pentahydrate (Na-GP), and hydroxyapatite powder (HAp) in a range of concentrations using the sol-gel method. The effect of HAp, Na-GP, and Ca-GP contents on the mechanical properties, i.e., Young's modulus, compressive strength, and yield strain, of hybrid composites was analyzed. The microstructure of the materials obtained was visualized by SEM. Moreover, the molecular interactions according to FTIR analysis and biocompatibility of composites obtained were examined. The CS/Si/HAp/Ca-GP developed from all composites analyzed was characterized by the welldeveloped surface of pores of two sizes: large ones of $100 \mu \mathrm{m}$ and many smaller pores below $10 \mu \mathrm{m}$, the behavior of which positively influenced cell proliferation and growth, as well as compressive strength in a range of 0.3 to $10 \mathrm{MPa}$, Young's modulus from 5.2 to $100 \mathrm{MPa}$, and volumetric shrinkage below $60 \%$. This proved to be a promising composite for applications in tissue engineering, e.g., filling small bone defects.
\end{abstract}

Keywords: chitosan; silica; hydroxyapatite; bone regeneration; calcium $\beta$-glycerophosphate; sodium $\beta$-glycerophosphate pentahydrate

\section{Introduction}

The development of innovative techniques and new biomaterials to fabricate porous, osteogenic, osteoconductive, osteoinductive, non-toxic, and biodegradable implants [1,2] with adequate mechanical strength is a challenge for many scientists, doctors, and engineers in the repair and treatment of bone tissue damaged by cancer, osteomyelitis, congenital defects, or accidents [3,4]. Composites based on ceramics (e.g., bioglasses, silica, hydroxyapatite, and titian), polymers (both natural and synthetic such as chitosan, collagen, fibrin, elastin, alginate, hyaluronic acid, polylactic acid) and hybrid bio-composites [5-13] are mainly used in bone tissue engineering applications. Chitosan is an ideal, inexpensive, and readily available copolymer of d-glucosamine and $\mathrm{N}$-acetyl-d-glucosamine [14] derived from the deacetylation of chitin [15] that can be used for the repair and treatment of damaged bone tissue [16]. This polymer is bioadhesive, biodegradable, biocompatible, and cytocompatible $[17,18]$, and supports the immune system by activating macrophages to produce anti-inflammatory cytokines $[19,20]$. Its low toxic effects and biological inertness have been confirmed in studies, both in vitro and in vivo [21]. However, scaffolds made only with chitosan as the base polymer are characterized by poor mechanical properties including poor tensile strength and low fracture stiffness, fast degradation rate, and low osteoconductivity [4]. Moreover, it is difficult to control pore size during the fabrication of chitosan implants, which play a key role in osteoblast survival, growth, and differentiation [22] as well as transport of essential components necessary for bone regeneration, gas diffusion, and removal of metabolism products. These disadvantages have been overcome 
by modifying chitosan-based implants with different substances (such as hydroxyapatite, sodium alginate, hyaluronic acid, calcium phosphate, collagen).

Hydroxyapatite (calcium hydroxyphosphate, $\left.\mathrm{Ca}_{10}\left(\mathrm{PO}_{4}\right)_{6}(\mathrm{OH})_{2}\right)$ is a bioceramic material that exhibits chemical and mineralogical similarity to the inorganic component of bones and teeth $[23,24]$. It is recognized as one of the better implantable materials in bone surgery and dentistry due to its biocompatible, osteoinductive, non-inflammatory, and bioresorbable nature [25]. The structural properties of hydroxyapatite significantly affect the mechanical and biological properties of bone in both in vitro and in vivo studies [26]. However, the degradation rate of synthetic hydroxyapatite is too slow, and the degradation rate of the material substrate may not match the growth rate of the tissue [3]. The addition of hydroxyapatite to the chitosan matrix can improve implant properties such as porosity, water retention, and osteoinductivity [27]. Qiaoling Hu et al. [28] have proved that the higher the hydroxyapatite content in the composite, the more brittle the composite is.

Currently, another promising component that exhibits properties ideal for grafting and scaffolding bone implants is silicon dioxide $\mathrm{SiO}_{2}$ or non-organic silica $[29,30]$. Three organic compounds are very often used as a source of silicate ions: tetraethylorthsilicate (TEOS) [6,31,32], ICPTES (3-isocyanatopropyl triethoxysilane) [31,32], and tetraacetoxysilane (TAS) [5]. Biomaterials based on polymers with silica have higher biomineralization capability than pure polymer. Silica also increases the stiffness of polymer material without significantly causing the mechanical strength of the composite to deteriorate. Silicon plays a significant role in the early stage of cartilage and bone growth and collagen synthesis by osteoblast cells. In addition, the silanol group also promotes the growth of new apatite on the bone substitute surface. Beck et al. [33] proved that silica stimulate bone-forming osteoblasts, suppress bone resorbing osteoclasts, and enhance bone mineral density in vivo. Based on the above properties, it can be expected that silica is an ideal component for improving mechanical properties, cell adhesion, proliferation, and biocompatibility of composite implants for bone regeneration. To our knowledge, biocomposites based on chitosan, hydroxyapatite, inorganic silica, and calcium $\beta$-glycerophosphate or sodium $\beta$-glycerophosphate pentahydrate have not been studied yet by researchers. Calcium $\beta$-glycerophosphate is used for the formation of calcium and phosphorus compounds (mineralization) in implants, which plays a crucial role in the development of both single cells and functional connections between them [34].

The present research is intended to fabricate a porous hybrid bio-composite having optimal bioactive and mechanical strength for bone implants, based on chitosan (CS) and non-organic silica (SI), reinforced with calcium $\beta$-glycerophosphate (Ca-GP) or sodium $\beta$ glycerophosphate pentahydrate (Na-GP), and hydroxyapatite powder (HAp). The sol-gel method and the convection drying method were applied to the fabrication of implants. The sol-gel method was used because it is highly adaptable and allows control of important properties of implants such as geometry, porosity, and the degree of pores in order to mimic the topological and microstructural characteristics of the extracellular matrix. It is widely known that after drying and rewetting, the initial moisture content of the composite does not return to its original internal structure $[35,36]$. The reason for this is that during drying the original structure is partially or totally destroyed by the action of surface tension of the solvent removed. Some chemical changes also take place such as the removal of hydroxyl groups from the surface of pores. Nevertheless, drying strengthens the solid, allowing for its storage, and provides the possibility of impregnation with bioactive ingredients. The study also investigated the influence of the drying temperature on the properties of composites. The composites obtained were characterized in terms of chemical and mechanical properties using an Instron universal testing machine, scanning electron microscopy (SEM), and Fourier-transform infrared (FTIR) spectroscopy. The biocompatibility of composites was also assessed. 


\section{Materials and Methods}

\subsection{Materials}

Medical grade chitosan powder (CS) from chitin of crab shells with molecular weight of $680 \mathrm{kDa}$ and degree of deacetylation of 80.4\% (Sigma-Aldrich, Germany) was used for the preparation of composites. Acetic acid, calcium $\beta$-glycerophosphate (Ca-GP), and sodium $\beta$-glycerophosphate pentahydrate (Na-GP) were purchased from Sigma-Aldrich (Germany), and hydroxyapatite (HAp, nanopowder, $<200 \mathrm{~nm}$ particle size) was acquired from Merck KGaA (Germany). Reagents except CS used in experiments were of analytical grade and used as received without further purification.

The source of inorganic silicon was sol of silica ( $\mathrm{Si}$, trade name Sizol 030) a commercial product of the "Rudniki" Chemical Works (Poland), essentially composed of $30 \% \mathrm{SiO}_{2}$ and $0.36 \% \mathrm{Na}_{2} \mathrm{O}$ in water, $\mathrm{pH} \sim 9$.

\subsection{Methods}

\subsubsection{Preparation of CS/Si/HAp Composites}

This fabrication method of CS/Si/HAp composites intended for bone substitutes is based on the sol-gel technique. Briefly, $0.4 \mathrm{~g}$ of chitosan was dissolved in $10 \mathrm{~g}$ of $4.0 \%$ acetic acid. The solution obtained was stirred (under slow rotations) until complete dissolution for $1 \mathrm{~h}$ in a water bath at $55^{\circ} \mathrm{C}$. Next, 3.2-12.7 wt.\% of hydroxyapatite was added gradually to the solution and stirred in an ultrasonic bath for 15 minutes to break down powder agglomerates. A total of $5.5 \mathrm{~g}$ of CS/HAp mixture was added dropwise to $11 \mathrm{~g}$ of silica sol and vigorously stirred. During the synthesis, the $\mathrm{pH}$ values of the solutions oscillated between 4 and 8 . Then, the paste obtained was poured into cylindrical PE molds with a diameter of $3 \mathrm{~cm}$ and height of $3 \mathrm{~cm}$ and aged for $24 \mathrm{~h}$. Finally, CS/Si/HAp composites were dried in one day at 50 and $100{ }^{\circ} \mathrm{C}$ in the oven at atmospheric pressure. After drying, the cylindrical samples were weighed and measured. Following the fabrication process, the composites obtained were subjected to chemical, mechanical, and biological assessment.

\subsubsection{Preparation of CS/Si/HAp/Ca-GP and CS/Si/HAp/Na-GP Composites}

The stages for preparation of CS/Si/HAp compositions described in Section 2.2.1. were repeated to obtain different CS/Si/HAp/Ca-GP and CS/Si/HAp/Na-GP composites with various weight ratios of Ca-GP and Na-GP. Briefly, 3.2-12.7 wt.\% of hydroxyapatite and 4.0-9.1 wt.\% of Na-GP were added gradually to the chitosan-acetic acid solution and stirred in an ultrasonic bath for 15 minutes. Then, CS/HAp/Na-GP mixtures were added to silica sol. The content of $\mathrm{SiO}_{2}$ was c.a. $20 \mathrm{wt}$.\%. Next, the pastes obtained were poured into cylindrical PE molds and aged for $24 \mathrm{~h}$. Finally, CS/HAp/Si/Na-GP composites were dried for $24 \mathrm{~h}$ at 50 and $100{ }^{\circ} \mathrm{C}$ in the oven at atmospheric pressure. In the case of the $\mathrm{CS} / \mathrm{Si} / \mathrm{HAp} / \mathrm{Ca}-\mathrm{GP}$ composites, the Ca-GP content was 3.3-8.2 wt.\%. After drying, the cylindrical samples were weighed, measured, and finally ground to obtain the desired dimensions for the next analysis. To maintain the stability of properties, samples were kept in desiccators with silica gel.

In the studies, the chitosan-acetic acid solution was prepared on the same day as the synthesis of samples. This eliminated the possible impact of degradation of chitosan on the properties of the composites obtained. For a comparison of mechanical properties of the obtained biocomposites, reference samples containing CS/Si, CS/Si/Ca-GP, and $\mathrm{CS} / \mathrm{Si} / \mathrm{Na}-\mathrm{GP}$ were also prepared according to proportions set out above, but the content of $\mathrm{SiO}_{2}$ was between 22.0 and $26.0 \mathrm{wt}$.\%.

\subsubsection{Determination of Density and Volumetric Shrinkage}

Densities of dry samples $\left(\rho_{\mathrm{s}}\right)$ of CS/Si, CS/Si/HAp, CS/Si/HAp/Ca-GP, CS/Si/Ca$\mathrm{GP}, \mathrm{CS} / \mathrm{Si} / \mathrm{HAp} / \mathrm{Na}-\mathrm{GP}, \mathrm{CS} / \mathrm{Si} / \mathrm{Na}-\mathrm{GP}$ were determined based on mass $\left(\mathrm{m}_{\mathrm{s}}\right)$ and volume of dry gels $\left(\mathrm{V}_{\mathrm{S}}\right)$, according to Equation (1):

$$
\rho_{\mathrm{s}}=\frac{\mathrm{m}_{\mathrm{s}}}{\mathrm{V}_{\mathrm{s}}}
$$


Skeletal densities were also determined using a helium pycnometer (AccuPyc 1330, Micromeritics Instrument Corporation, Norcross, GA, USA).

The volumetric shrinkage coefficient $(\sigma)$ as a percentage $(\%)$ for each sample was calculated using the formula (Equation (2)),

$$
\sigma=\left(1-\mathrm{V}_{\mathrm{s}} / \mathrm{V}_{\mathrm{m}}\right) \cdot 100 \%
$$

where $V_{s}$ is the volume of the dry cylindrical sample and $V_{m}$ is the volume of the wet sample.

\subsubsection{Mechanical Testing of Composites}

Mechanical properties of CS/Si, CS/Si/HAp, CS/Si/HAp/Ca-GP, CS/Si/Ca-GP, $\mathrm{CS} / \mathrm{Si} / \mathrm{HAp} / \mathrm{Na}-\mathrm{GP}$, and $\mathrm{CS} / \mathrm{Si} / \mathrm{Na}-\mathrm{GP}$ biocomposites were investigated at room temperature using a computer-controlled universal testing machine (Instron 2519-107, USA) at maximum load $5 \mathrm{kN}$ and constant speed of crosshead displacement $0.2 \mathrm{~mm} / \mathrm{min}$. Before the tests, each cylindrical sample was ground after drying to align the upper and lower surface. The initial length of the specimens was $15 \pm 0.1 \mathrm{~mm}$. A mean value of at least five different measurements was obtained, and a standard deviation was calculated. Young's modulus values were determined from the slope of the linear part of stress-strain curves, and compressive strength was obtained from the first maximum of stress visible in the curves.

\subsubsection{Surface Analysis of Composites}

The surface morphology of CS/Si, CS/Si/HAp, CS/Si/HAp/Ca-GP, CS/Si/Ca-GP, $\mathrm{CS} / \mathrm{Si} / \mathrm{HAp} / \mathrm{Na}-\mathrm{GP}$, and CS/Si/Na-GP nanocomposites was investigated using scanning electron microscopy (FEI model Quanta 200F, Thermo Fisher Scientific, Hillsboro, OR, USA), coupled with a field emission gun (FEG) and energy dispersive spectroscopy (EDS) equipment (EDAX model Genesis 4000). Experiments were performed under a nitrogen atmosphere at a pressure of $100 \mathrm{~Pa}$ (low vacuum operating mode). This mode avoids coating the sample with a thin conductive layer, such as gold or carbon, which is important in order not to distort the surface topography.

\subsubsection{Structure Characterization of Composites}

Attenuated total reflection Fourier-transform infrared (ATR-FTIR) spectroscopy was applied to characterize intermolecular interactions between components included in the composites. The spectra of the pure components used in synthesis and spectra for the prepared composites were recorded. The ATR-FTIR spectra were recorded in the 4000 to $650 \mathrm{~cm}^{-1}$ range using a Jasco FT/IR 6200 spectrometer (JASCO Inter. Co., Ltd., Tokyo, Japan) equipped with an MCT M detector cooled by liquid nitrogen (77K) and a MIRacle ATR sampling accessory (diamond/ZnSe) (PIKE Technol., Fitchburg, WI, USA). The whole spectrometric system was purged by dry argon. The interferometer scanning rate was $0.1 \mathrm{~cm} / \mathrm{s}$. Signal accumulation from 300 scans was taken with a resolution of $1 \mathrm{~cm}^{-1}$. The test specimens were in the form of powder, without previous compression.

\subsubsection{Biocompatibility Analysis of Compositions}

KYOU DXR0109B human induced pluripotent stem (IPS) cells [201B7] (ATCC ${ }^{\circledR}$ ACS1023 ${ }^{\mathrm{TM}}$; Manassas, VA, USA) derived from fibroblasts obtained from a healthy donor were used for the study. Prior to testing, all culture vessels and samples of the tested composites were coated with CellMatrix ${ }^{\mathrm{TM}}$ Basement Membrane Gel, (ATCC ACS3035) to enable cell adhesion, according to the guidelines provided by the vendors.

The culture was carried out in Eppendorf tubes (cell culture plates, size 12 wells, surface treatment TC treated, flat bottom clear wells) on 12-well plates. An implant was placed from each type of test composite used in standard culture vessels, and then a 20,000 cells $/ \mathrm{cm}^{2}$ area was flooded with $2 \mathrm{~mL}$ of the Pluripotent Stem Cell SFM XF/FF culture medium (ATCC ACS3002). The culture was carried out in an incubator (PHCBI CytoGrow incubator, Panasonic) at $37^{\circ} \mathrm{C}, 95 \%$ humidity, in the presence of $5 \% \mathrm{CO}_{2}$. Cells 
were incubated for 7 days (according to the ATCC ${ }^{\circledR}$ recommendation, KYOU DXR0109B cell culture time between passages) in the presence of the test biomaterials relative to a control culture under standard conditions. The culture medium was changed daily, and the suspended cells present in the medium were harvested, counted, and evaluated for viability. Cells were harvested using a stem cell dissociation reagent (ATCC ACS3010), and the number of viable cells was assessed using a Trypan Blue assay (BioRad) and a TC20 ${ }^{\mathrm{TM}}$ Automated Cell Counter (BioRad). Statistical analysis was performed using Student's t-tests for independent samples and the ANOVA method. Tests were repeated three times for each sample and control.

\section{Results and Discussion}

\subsection{Morphological Characteristics}

The sol-gel method applied allows bone composites to be obtained. Examples of CS/Si/HAp, CS/Si/HAp/Na-GP, CS/Si/Na-GP, and CS/Si/HAp/Ca-GP samples can be seen in Figure 1.

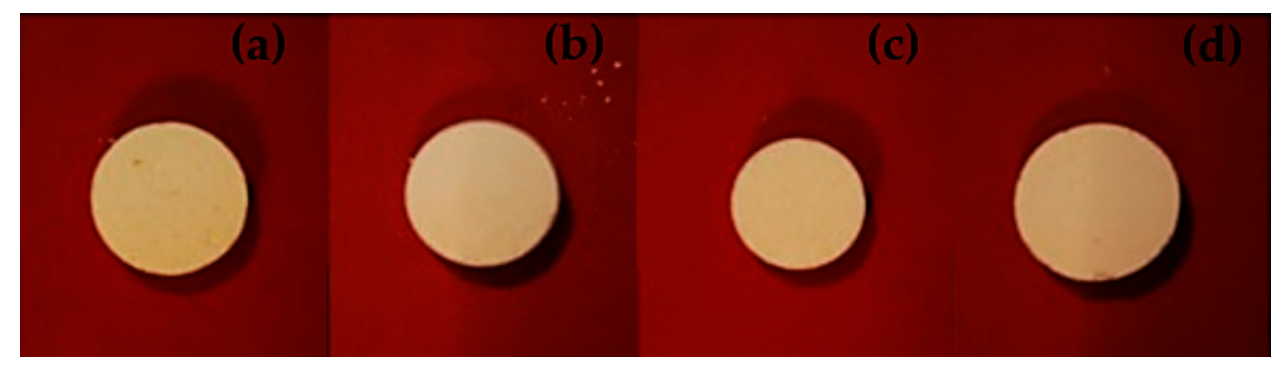

Figure 1. Example photograph of composites fabricated by the sol-gel method (a) CS/Si/HAp; (b) CS/Si/HAp/Na-GP; (c) CS/Si/Na-GP; (d) CS/Si/HAp/Ca-GP.

The resulting composites had a three-dimensional structure, but the color, porosity, and stiffness were different. The color of the implants varied; the hydroxyapatite-based implants were whiter than the non-hydroxyapatite implants. A higher concentration of hydroxyapatite resulted in a greater porosity of the structure and thus a more complex external topography. Appropriate surface chemistry and a highly porous structure of the implants are needed to support cell growth, adhesion, proliferation, oxygen, and nutrient diffusion and remove metabolic waste produced during the bone tissue regeneration process. Porosity more significant than $75 \%$ is required to obtain osteoconductive properties of composites [3]. In order to assess the structural differences of the implants, photos were taken using SEM. Figure 2 presents example SEM images of the structures obtained of $\mathrm{CS} / \mathrm{Si} / \mathrm{HAp} / \mathrm{Ca}-\mathrm{GP}, \mathrm{CS} / \mathrm{Si} / \mathrm{HAp} / \mathrm{Na}-\mathrm{GP}, \mathrm{CS} / \mathrm{Si} / \mathrm{HAp}$, and CS/Si composites that can be applied for bone tissue regeneration. The SEM image control showed that the surface of CS/Si (Figure 2d) was smooth, while those of CS/Si/HAp/Na-GP (Figure 2b) and $\mathrm{CS} / \mathrm{Si} / \mathrm{HAp}$ (Figure 2c) were rough with slots with pores size below $10 \mu \mathrm{m}$. However, the surface of the CS/Si/HAp/Ca-GP (Figure 2a) composite was rough, with corrugation and cornification with a well-developed microstructure. This composite is characterized as having pores of two sizes: large ones of $100 \mu \mathrm{m}$ and many smaller pores below $10 \mu \mathrm{m}$, the behavior of which should positively influence cell proliferation and growth. 

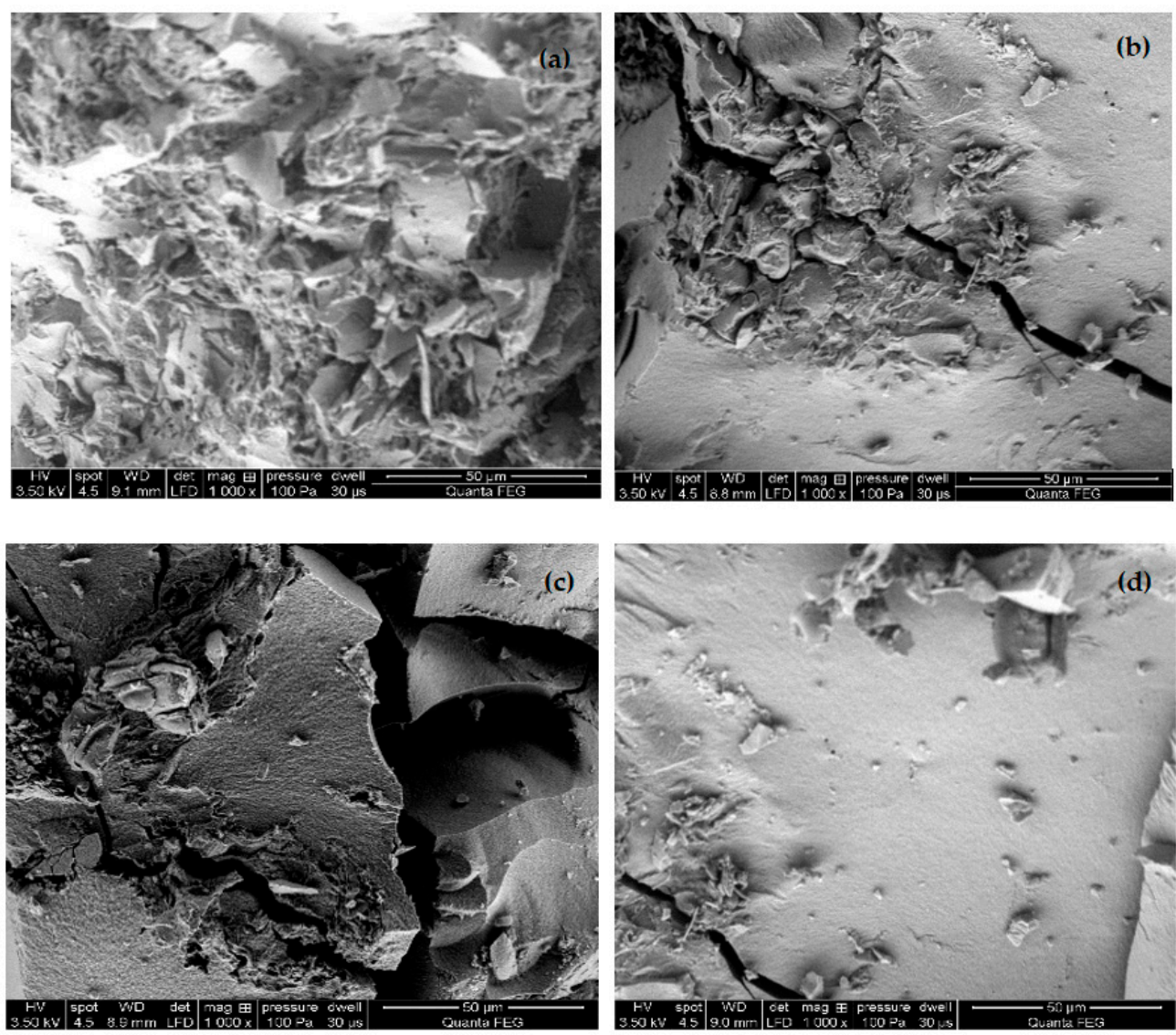

Figure 2. Example SEM images of (a) CS/Si/HAp/Ca-GP; (b) CS/Si/HAp/Na-GP; (c) CS/Si/HAp; (d) CS/Si composites with a similar concentration of HAp.

\subsection{Mechanical Assessment}

The mechanical properties of the implants after drying at 50 and $100{ }^{\circ} \mathrm{C}$ were investigated at ambient temperature. The effect of the HAp, Na-GP, and Ca-GP contents on the mechanical properties of hybrid composites was analyzed. Young's modulus, strain, and compressive strength of $\mathrm{CS} / \mathrm{Si} / \mathrm{HAp}$ composites are presented in Figure 3. The mechanical properties of $\mathrm{CS} / \mathrm{Si} / \mathrm{HAp}$ composites in terms of Young's modulus significantly increased when increasing the concentration of HAp in the sample and reached a maximum concentration of $1.0 \mathrm{wt} . \%$. The value of modulus decreased, suggesting a poor interfacial bonding between HAp particles and CS/Si molecules. The results of compression tests showed that the addition of HAp to CS/Si composite promoted compressive strength while causing a decrease in elongation at break. The highest value of Young's modulus of $25 \mathrm{MPa}$ for $\mathrm{CS} / \mathrm{Si} / \mathrm{HAp}$ composites was obtained for drying samples at $100{ }^{\circ} \mathrm{C}$ and $71 \mathrm{MPa}$ for $50^{\circ} \mathrm{C}$. 

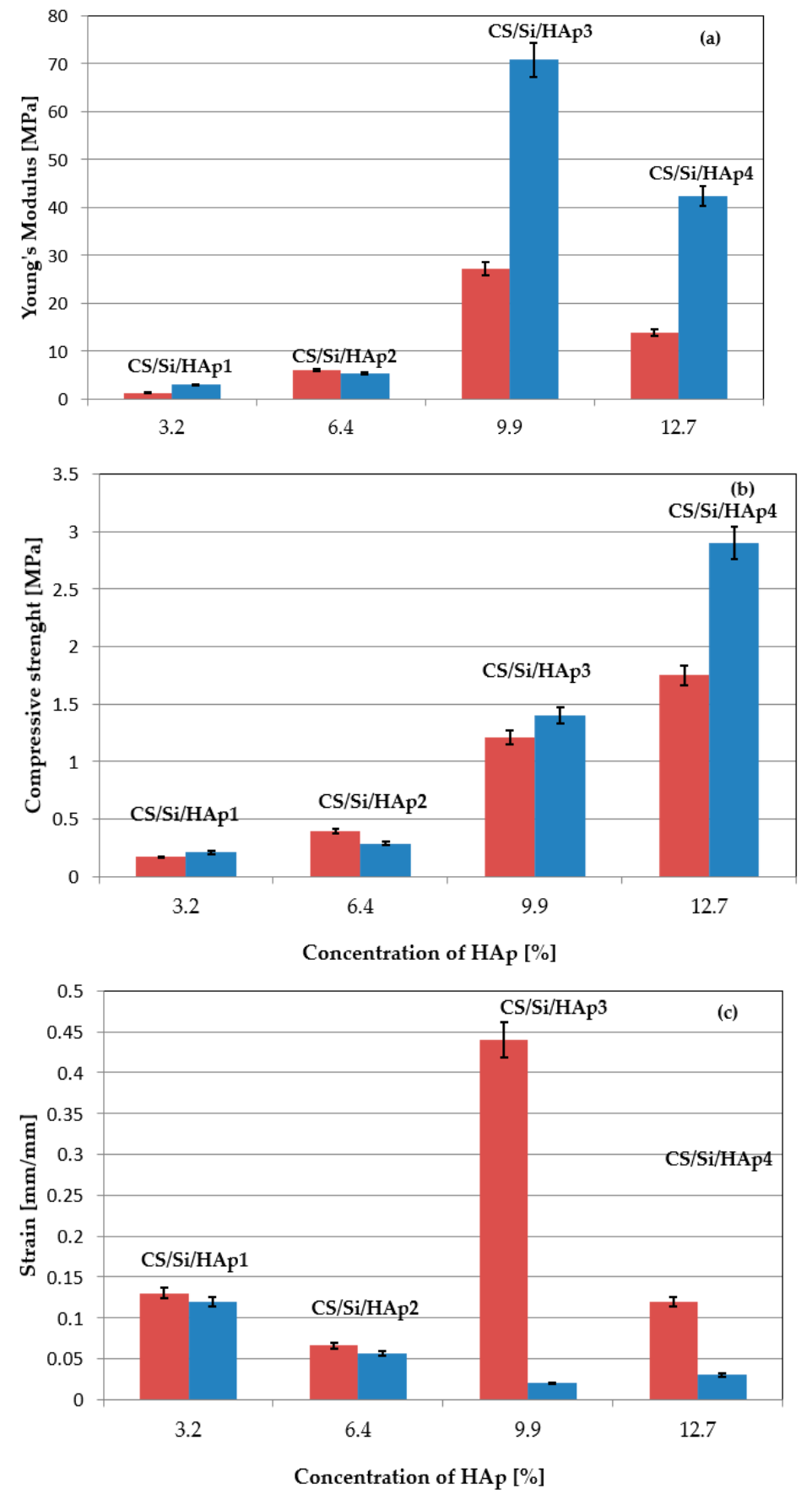

Figure 3. Dependence of Young's modulus (a), compressive strength (b), strain (c) vs. concentration of hydroxyapatite with $20 \mathrm{wt} . \% \mathrm{SiO}_{2}$ and $0.7-1.1 \mathrm{wt} . \%$ chitosan. The drying of samples at a temperature of $100{ }^{\circ} \mathrm{C}$ is marked in blue and at $50{ }^{\circ} \mathrm{C}$ in red.

In the study, the influence of drying temperature on the mechanical properties of the developed composites was noted and is shown in Figure 3. The results obtained of Young's modulus in case of drying the sample at a temperature of $100{ }^{\circ} \mathrm{C}$ were lower compared to $50{ }^{\circ} \mathrm{C}$. In the bar graph in Figure 4, the Young's modulus values for CS/Si/Na-GP and $\mathrm{CS} / \mathrm{Si} / \mathrm{HAp} / \mathrm{Na}-\mathrm{GP}$ composites are compared. Analyzing results for the samples of $\mathrm{CS} / \mathrm{Si} / \mathrm{Na}-\mathrm{GP}(1-4)$, we can see that the higher concentration of Na-GP in a sample, the lower the value of Young's modulus. 


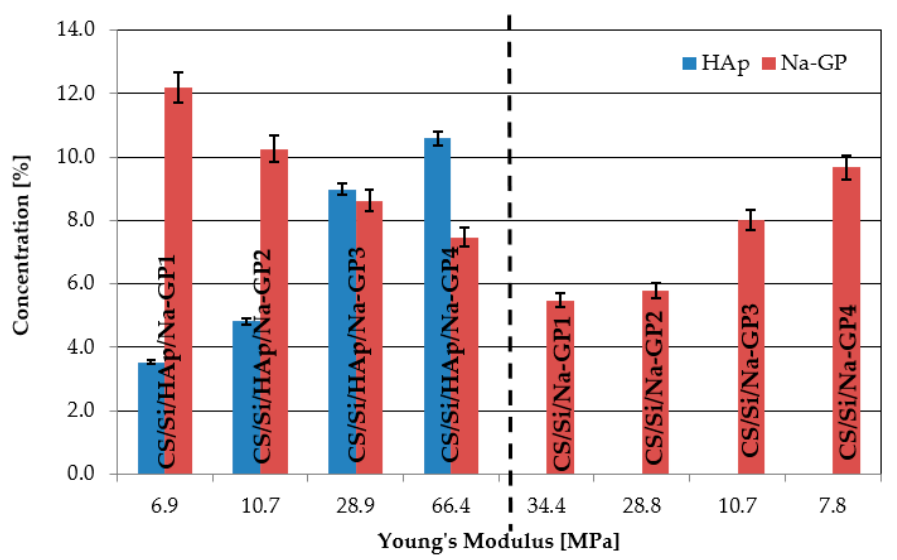

Figure 4. Influence of HAp and Na-GP concentrations on Young's modulus (labels above each composite) for drying samples at $100^{\circ} \mathrm{C}$.

A similar situation was observed for CS/Si/HAp/Na-GP composites, but this case is more complicated. During the fabrication of CS/Si/HAp/Na-GP and CS/Si/Na-GP composites, the concentrations of $\mathrm{SiO}_{2}$ and chitosan were at the same level, but concentrations of HAp and Na-GP were different. Though the CS/Si/HAp/Na-GP composites exhibited better mechanical properties than $\mathrm{CS} / \mathrm{Si} / \mathrm{HAp}$ or CS/Si/Na-GP, the presence of Na-GP weakened the composite. Based on the results presented in Figure 4, it can be concluded that in samples with higher concentrations of HAp, Young's modulus was higher than in samples with higher concentrations of Na-GP. The peak value of Young's modulus for these composites was $66.44 \pm 3.32 \mathrm{MPa}$.

A completely different trend was observed for the composites doped with Ca-GP. The values of Young's modulus increased after mixing with Ca-GP, but this trend heavily depended on the concentration of both Ca-GP and HAp as illustrated in Figure 5. For samples with Ca-GP without HAp, a twofold increase in the concentration of Ca-GP causes a slight increase in Young's modulus. On the other hand, for composites with $7.7 \mathrm{wt} \%$ of Ca-GP and $5.0 \mathrm{wt} . \%$ of HAp, the peak value of Young's modulus of $100.75 \pm 4.99 \mathrm{MPa}$ was determined in the group of all tested configurations.

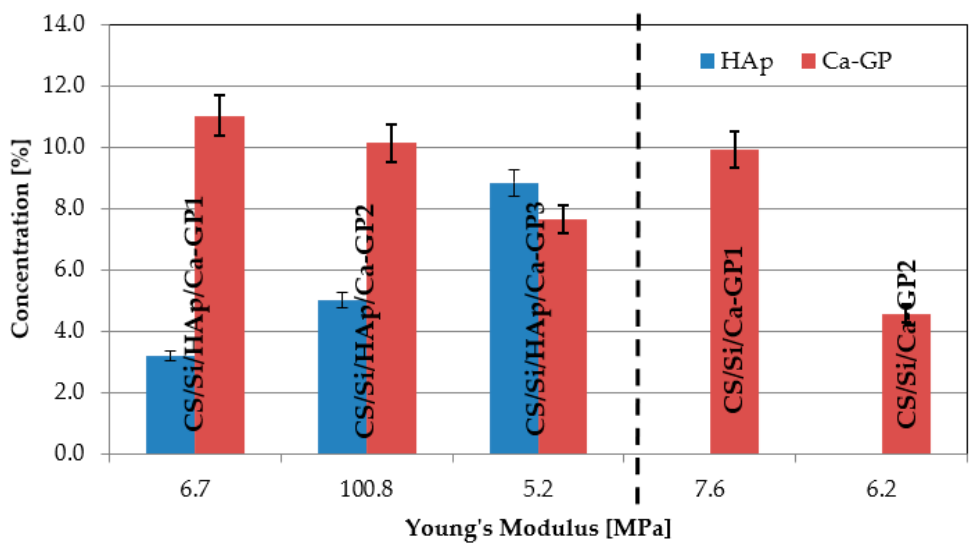

Figure 5. Influence of hydroxyapatite and Ca-GP on Young's modulus (labels above each composite) for drying samples at $100^{\circ} \mathrm{C}$.

For comparison, the work of Sowjanya [37] presented composites based on chitosan, reinforced with nanosilica powder and sodium alginate, which were characterized by compressive strength in a range of 0.59 to $0.66 \mathrm{MPa}$ and Young's modulus of 8.16 to $8.99 \mathrm{MPa}$. Composites obtained in the present work were characterized by compressive strength in a range of 0.3 to $15 \mathrm{MPa}$, while the cancellous bone is characterized by a modulus of 0.8 to $1000 \mathrm{MPa}$, and the compressive strength of human bone is 1 to $210 \mathrm{MPa}$. 
The Young's modulus results obtained for CS/Si/HAp, CS/Si/HAp/Ca-GP, CS/Si/Ca$\mathrm{GP}, \mathrm{CS} / \mathrm{Si} / \mathrm{HAp} / \mathrm{Na}-\mathrm{GP}, \mathrm{CS} / \mathrm{Si} / \mathrm{Na}-\mathrm{GP}$ were compared to CS/Si reference composites. The composition and properties of CS/Si are presented in Table 1. These samples were characterized by a very low Young's modulus and compressive strength.

Table 1. Properties of references samples of CS/Si.

\begin{tabular}{|c|c|c|c|c|c|c|c|}
\hline Sample & $\begin{array}{c}\text { Chitosan } \\
\text { (wt.\%) }\end{array}$ & $\begin{array}{c}\mathrm{SiO}_{2} \\
\text { (wt.\%) }\end{array}$ & $\begin{array}{c}\text { Young's } \\
\text { Modulus (MPa) }\end{array}$ & $\begin{array}{l}\text { Compressive } \\
\text { Strength (MPa) }\end{array}$ & $\begin{array}{c}\text { Strain } \\
(\mathrm{mm} / \mathrm{mm})\end{array}$ & $\begin{array}{c}r_{s} \\
\left(g / \mathrm{cm}^{3}\right)\end{array}$ & $\begin{array}{c}\mathrm{V}_{\mathrm{s}} / \mathrm{V}_{\mathrm{m}} \\
(\%)\end{array}$ \\
\hline CS/Si 1 & 0.66 & 24.84 & $0.39 \pm 0.04$ & $0.016 \pm 0.004$ & $0.04 \pm 0.001$ & $0.40 \pm 0.04$ & $3.5 \pm 0.32$ \\
\hline CS/Si 2 & 0.76 & 24.07 & $1.55 \pm 0.13$ & $0.003 \pm 0.001$ & $0.002 \pm 0.001$ & $0.35 \pm 0.03$ & $12.9 \pm 0.04$ \\
\hline $\mathrm{CS} / \mathrm{Si} 3$ & 0.96 & 22.53 & $2.06 \pm 0.15$ & $1.13 \pm 0.15$ & $0.55 \pm 0.09$ & $0.38 \pm 0.04$ & $0.8 \pm 0.02$ \\
\hline $\mathrm{CS} / \mathrm{Si} 4$ & 1.12 & 21.27 & $0.36 \pm 0.09$ & $0.009 \pm 0.001$ & $0.02 \pm 0.001$ & $0.37 \pm 0.04$ & $27.1 \pm 1.44$ \\
\hline
\end{tabular}

The content of HAp and/or x-GP (where $x$ is Na or $\mathrm{Ca}$ ) to chitosan has a strong effect on the mechanical properties of implants. All the above results suggest that alteration of mechanical properties is a consequence of the interaction between chitosan, silica sol, and components based on calcium. Better mechanical properties can be a result of crosslinking reactions within chains of chitosan and molecular interaction between biopolymer and silica, which stiffens the skeleton of the composite.

\subsection{Density and Volumetric Shrinkage}

Densities of dry samples of CS/Si, CS/Si/HAp, CS/Si/HAp/Ca-GP, CS/Si/Ca-GP, $\mathrm{CS} / \mathrm{Si} / \mathrm{HAp} / \mathrm{Na}-\mathrm{GP}$, and CS/Si/Na-GP were calculated using Equation (1), and volumetric shrinkages were estimated using Equation 2. Densities obtained of CS/Si, CS/Si/HAp, CS/Si/HAp/Ca-GP, CS/Si/Ca-GP, CS/Si/HAp/Na-GP, and CS/Si/Na-GP implants were in the range of 320 to $820 \mathrm{~kg} / \mathrm{m}^{3}$, which is comparable to density of cancellous bone which ranges from 300 to $2100 \mathrm{~kg} / \mathrm{m}^{3}$ depending on age of the person. The drying temperature had an impact on the results of the density and volumetric shrinkage of the materials obtained. Drying samples at $100{ }^{\circ} \mathrm{C}$ reduces the volume shrinkage by $50 \%$ as shown in Figure 6 and increases the density of the samples compared to drying at $50{ }^{\circ} \mathrm{C}$. In addition, the volumetric shrinkage of samples also depends on content and composition and is within a range of $5 \%$ to $45 \%$. The experimental data obtained are difficult to describe by explicit functional dependence. An additional series of measurements to characterize the trend in the course of the volumetric shrinkage needs to be performed. In most cases, composites with Na-GP characterized the lowest volumetric shrinkage compared with composites of CS/Si, CS/Si/HAp, CS/Si/HAp/Ca-GP, and CS/Si/Ca-GP.

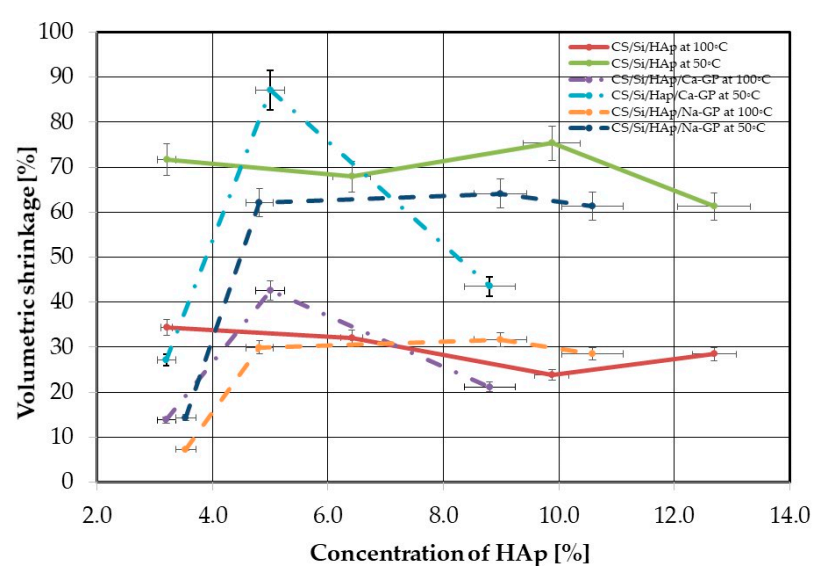

Figure 6. Volumetric shrinkage of CS/Si/HAp, CS/Si/Ca-GP, CS/Si/HAp/Ca-GP composites at drying temperature of 50 and $100{ }^{\circ} \mathrm{C}$.

CS/Si/HAp, CS/Si/Ca-GP, CS/Si/HAp/Ca-GP implants were chosen as the most promising composites for further FTIR analysis and biological studies. 


\subsection{FTIR Analysis}

The molecular interactions of CS/Si/HAp, CS/Si/Ca-GP, and CS/Si/HAp/Ca-GP implants were studied by FTIR analysis. Figure 7 shows spectra of composites obtained and represents the range of individual components used in fabrication. Differences are observed between pure components and composites.
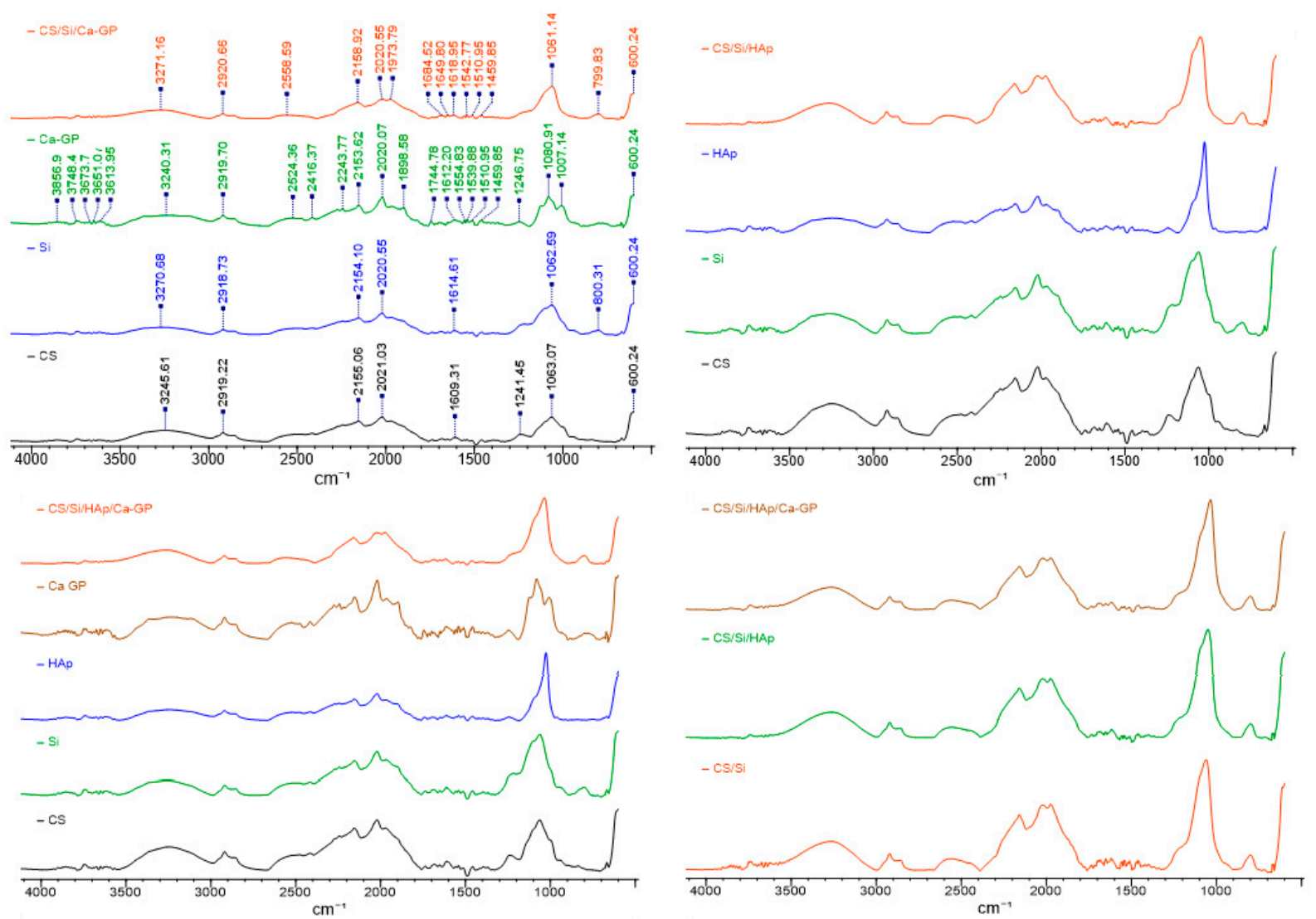

Figure 7. FTIR characterization of implants made of CS/Si/HAp, CS/Si/Ca-GP, CS/Si/HAp/Ca-GP.

The spectrum obtained for chitosan powder samples shows typical bands, such as a broad band in the region of $3500-3000 \mathrm{~cm}^{-1}$ corresponding to an overlap of $\mathrm{OH}$ group vibration and $\mathrm{NH}$ group vibration stretching. A characteristic peak at $2919.2 \mathrm{~cm}^{-1}$ is indicative of the $\mathrm{C}-\mathrm{H}$ bond vibration antisymmetric stretching. An N-H chemical bond in the primary amine and secondary amide occurred at $1540 \mathrm{~cm}^{-1}$. Deforming, antisymmetric vibrations for the $\mathrm{C}-\mathrm{H}$ bond were confirmed by a peak at $1458 \mathrm{~cm}^{-1}$ and stretching vibration for N-C-O by a peak at $1241.5 \mathrm{~cm}^{-1}$. The band for the C-O group vibration stretching (amide I band) was confirmed by a peak at $1651.2 \mathrm{~cm}^{-1}$, and vibration stretching for the C-O-C group by a peak at $1063.07 \mathrm{~cm}^{-1}$.

The infrared spectra of raw HAp powder exhibit characteristic absorption bands such as a broad band in the region of $3500-3000 \mathrm{~cm}^{-1}$ with a peak at $3245 \mathrm{~cm}^{-1}$ corresponding to the vibration of the $\mathrm{OH}$ group as a result of water in hydroxyapatite and adsorbed by components from the atmosphere. P-O stretching vibration at $1236 \mathrm{~cm}^{-1}$ and $\mathrm{P}-\mathrm{O}$ asymmetric stretching vibration (the $\mathrm{PO}_{4}{ }^{3-} v 1$ mode) appeared at $1026 \mathrm{~cm}^{-1}$.

For spectra of Sizol, a peak at $3270 \mathrm{~cm}^{-1}$ for the surface $\mathrm{OH}$ group can be observed. The presence of the Si-H stretching bond is confirmed by the peak at $2154 \mathrm{~cm}^{-1}$ and that at $1062.59 \mathrm{~cm}^{-1}$, equivalent to Si-O-C stretching bond (open chain) or Si-O-Si symmetric stretching bond vibration.

The Ca-GP spectrum showed that for a peak at $1250 \mathrm{~cm}^{-1}, \mathrm{C}-\mathrm{C}$ skeletal vibrations overlap with the P-O stretching bond. The C-O and P-O-R stretching bands were confirmed by peaks at 1253 and $1005 \mathrm{~cm}^{-1}$. 
The composite CS/Si/Ca-GP shows several differences compared with the spectra of pure components. The band at $2020.55 \mathrm{~cm}^{-1}$ is less pronounced, while bands in the region of 1770-1320 $\mathrm{cm}^{-1}$ become sharper. In spectra for a composite, the peaks at 1241.45 and at $946.4 \mathrm{~cm}^{-1}$ are less distinct. The band at $2415.89 \mathrm{~cm}^{-1}$ (corresponding to O-H group stretching vibration) disappears completely, while the band at $2558.59 \mathrm{~cm}^{-1}$ becomes more pronounced (N-H in amine salts). This could indicate that $\mathrm{Si}$ atoms join the group $\mathrm{OH}$ in chitosan. The peak at $1061.14 \mathrm{~cm}^{-1}$ is more significant and smooth. Furthermore, the band shift from 1063.07 to $1061.14 \mathrm{~cm}^{-1}$ indicates some interaction in symmetric bond vibration Si-O-Si.

For composites CS/Si/HAp, FTIR spectra show similar differences as described above for CS/Si/Ca-GP composites. A new peak appears at $2557.15 \mathrm{~cm}^{-1}$, the peak at $2415.88 \mathrm{~cm}^{-1}$ disappears, and the peak at $1049.57 \mathrm{~cm}^{-1}$ is more significant. Furthermore, a double peak appears instead of a single peak at $669.41 \mathrm{~cm}^{-1}$. The band shift from 1063.07 to $1049.57 \mathrm{~cm}^{-1}$ indicates some interaction with the symmetric bond Si-O-Si. The band shift is also observed for $\mathrm{OH}$ group vibration, and the peak for this group in the CS/Si/HAp composite is at $3261.52 \mathrm{~cm}^{-1}$ (for CS at $3245.61 \mathrm{~cm}^{-1}$, Si at $3270.68 \mathrm{~cm}^{-1}$, and HAp at $3244.65 \mathrm{~cm}^{-1}$ ).

The CS/Si/HAp/Ca-GP composite exhibited similar behavior. The band at $2560.56 \mathrm{~cm}^{-1}$ becomes more pronounced. A significant band shift is also observed for $\mathrm{OH}$ group vibration, and the peak is at $3260.56 \mathrm{~cm}^{-1}$ (where for Ca-GP it is at $3240.31 \mathrm{~cm}^{-1}$ and the peak is flatter than for other pure components and composites). In the case of $\mathrm{Si}-\mathrm{O}-\mathrm{Si}$, a shift is observed from 1063.07 to $1035.10 \mathrm{~cm}^{-1}$.

Comparing spectra of composites, for CS/Si/Ca-GP and CS/Si/HAp we can observe a double peak at $670 \mathrm{~cm}^{-1}$, while for CS/Si/HAp/Ca-GP for the same wave number a single peak is observed. The bands in the region of $1800-1300 \mathrm{~cm}^{-1}$ are sharper for CS/Si composites than for other composites analyzed. In each case, the band shift for $\mathrm{OH}$ band vibration and $\mathrm{Si}-\mathrm{O}-\mathrm{Si}$ vibration indicates interaction between the $\mathrm{Si}$ atom and the $\mathrm{OH}$ group. The highest value for this shift is obtained when Ca-GP is added to the composite, and for this sample, the calculated value of Young's modulus was the highest. The new bond between $\mathrm{Si}$ and the $\mathrm{OH}$ group reinforces the composite.

In all probability, a very high concentration of Sizol in composites, in comparison with other components, and the possibility of precipitating crystals can impair molecular interactions.

\subsection{In Vitro Study}

The composite's essential characteristics, determining its suitability for bone tissue applications, are its biocompatibility and cytotoxicity, which require both in vitro studies on isolated, well-defined cells or tissues in laboratory conditions and in vivo testing on animals. In vitro tests are inexpensive and allow initial results of the cell reaction to the tested composite to be obtained quickly. In this study, fibroblast cells were used in cytotoxicity and biocompatibility tests of CS/Si/HAp, CS/Si/Ca-GP, and CS/Si/HAp/CaGP composites. Results obtained of cell growth, proliferation, and viability are displayed in Figure 8. 

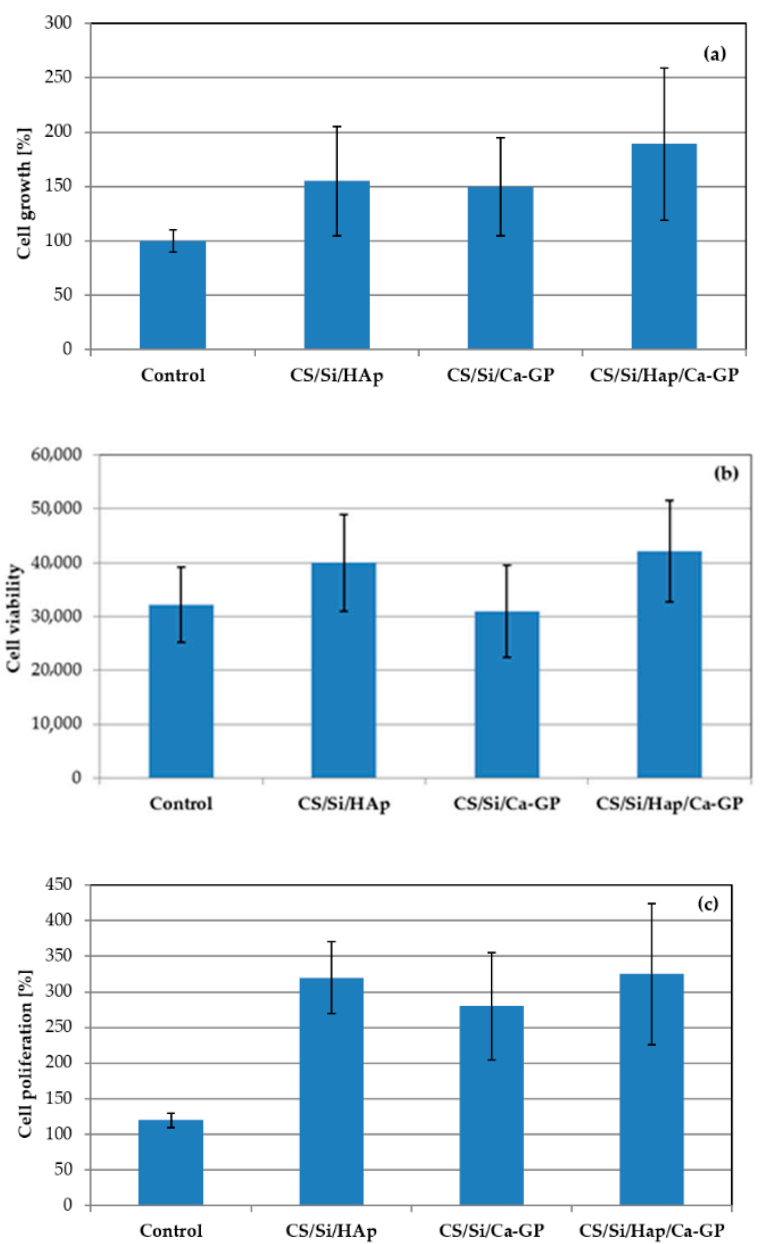

Figure 8. Cell growth (a), viability (b), and proliferation results (c) of CS/Si/HAp, CS/Si/Ca-GP, $\mathrm{CS} / \mathrm{Si} / \mathrm{HAp} / \mathrm{Ca}-\mathrm{GP}$ composites.

The growth of fibroblasts after 7 days of cell culture was compared to cells cultured without composites (control, $p>0.05$ ). The lowest mean value of cell growth (Figure $8 \mathrm{a}$ ) among the composites tested was recorded in a well with CS/Si/HAp (149\%), but the differences are not statistically significant compared to the control. The highest cell growth was observed in the wells with CS/Si/HAp/Ca-GP composite due to its good mechanical properties, highly porous microstructure (greater than $75 \%$ ), and surface roughness. There were additional perforations in the walls of the pores CS/Si/HAp/Ca-GP composite, which are necessary for proper cell growth, cell migration, and mass transport. The cell proliferation assay indicated that none of the CS/Si/HAp, CS/Si/Ca-GP, or CS/Si/HAp/Ca-GP composites caused a cytotoxic effect, confirmed by the lack of cell death in comparison to the control $(100 \%$ of viability). The highest cell viability and proliferation were also observed in the CS/Si/HAp/Ca-GP composite. The results obtained of structural, mechanical, and biological investigation of composites showed that the CS/Si/HAp/Ca-GP composite has promising potential in biomedical applications such as bone regeneration, and therefore animal tests can be considered. 


\section{Conclusions}

In this study, a new, patented method of fabrication of bio-hybrid Cs/Si, CS/Si/HAp, CS/Si/HAp/Ca-GP, CS/Si/Ca-GP, CS/Si/HAp/Na-GP, and CS/Si/Na-GP composites using the sol-gel technique was developed. The basic structural, mechanical, and biological properties of composites obtained were investigated through FTIR, SEM, and the Instron universal testing machine. Of all composites analyzed, the CS/Si/HAp/Ca-GP composite obtained was the most promising for further research in the field of biomaterials for bone tissue regeneration. It was characterized by the well-developed surface of pores of two sizes: large ones of $100 \mu \mathrm{m}$ and many smaller pores below $10 \mu \mathrm{m}$, the behavior of which positively influenced cell proliferation and growth, as well as a density comparable to the bone density, compressive strength of $0.3-10 \mathrm{MPa}$, Young's modulus of 5-100 MPa, and volumetric shrinkage below $60 \%$. The CS/Si/HAp/Ca-GP composite had an appropriate morphology and did not show cytotoxicity towards the tested fibroblasts. Positive test results predispose the material to be suitable for animal testing.

The study showed significant dependence on the drying temperature mainly on the resulting structure's physicochemical properties of composites. Drying samples at $100{ }^{\circ} \mathrm{C}$ reduced the volume shrinkage by $50 \%$ and increased the density and mechanical properties of the samples compared to drying at $50{ }^{\circ} \mathrm{C}$. However, it was noticed that the use of hightemperature convection drying at atmospheric pressure is an advantage because it reduces the costs of obtaining the biomaterial and can also replace the sterilization process. In future research, drying strategies should be designed to achieve optimal physicochemical properties of the implants for bone tissue regeneration.

Author Contributions: Conceptualization, R.A. and D.S.; methodology, R.A.; resources, R.A.; investigation, R.A. and D.S.; writing-original draft preparation, R.A. and D.S.; writing—review and editing, D.S. All authors have read and agreed to the published version of the manuscript.

Funding: The study was supported by the Faculty of Process and Environmental Engineering at Lodz University of Technology.

Institutional Review Board Statement: Not applicable.

Informed Consent Statement: Not applicable.

Data Availability Statement: The data presented in this study are available on request from the corresponding author.

Acknowledgments: The authors thank Anna Adamska for assisting in mechanical and cytotoxicity tests.

Conflicts of Interest: The authors declare no conflict of interest.

\section{References}

1. Przekora, A.; Palka, K.; Ginalska, G. Chitosan/ $\beta-1,3$-glucan/calcium phosphate ceramics composites-Novel cell scaffolds for bone tissue engineering application. J. Biotechnol. 2014, 182-183, 46-53. [CrossRef] [PubMed]

2. Umar Aslam Khan, M.; Haider, S.; Haider, A.; Izwan Abd Razak, S.; Rafiq Abdul Kadir, M.; Shah, S.A.; Javed, A.; Shakir, I.; Al-Zahrani, A.A. Development of porous, antibacterial and biocompatible GO/n-HAp/bacterial cellulose/ $\beta$-glucan biocomposite scaffold for bone tissue engineering. Arab. J. Chem. 2021, 14, 102924. [CrossRef]

3. Keller, L.; Regiel-Futyra, A.; Gimeno, M.; Eap, S.; Mendoza, G.; Andreu, V.; Wagner, Q.; Kyzioł, A.; Sebastian, V.; Stochel, G.; et al. Chitosan-based nanocomposites for the repair of bone defects. Nanomed. Nanotechnol. Biol. Med. 2017, 13, 2231-2240. [CrossRef] [PubMed]

4. Vaidhyanathan, B.; Vincent, P.; Vadivel, S.; Karuppiah, P.; AL-Dhabi, N.A.; Sadhasivam, D.R.; Vimalraj, S.; Saravanan, S. Fabrication and investigation of the suitability of chitosan-silver composite scaffolds for bone tissue engineering applications. Process Biochem. 2021, 100, 178-187. [CrossRef]

5. Yazdanpanah, Z.; Bahrololoom, M.E.; Hashemi, B. Evaluating morphology and mechanical properties of glass-reinforced natural hydroxyapatite composites. J. Mech. Behav. Biomed. Mater. 2015, 41, 36-42. [CrossRef]

6. Sathain, A.; Monvisade, P.; Siriphannon, P. Bioactive alginate/carrageenan/calcium silicate porous scaffolds for bone tissue engineering. Mater. Today Commun. 2021, 26, 102165. [CrossRef]

7. Prasad, A. State of art review on bioabsorbable polymeric scaffolds for bone tissue engineering. Mater. Today Proc. 2021. [CrossRef]

8. Corrales, L.P.; Esteves, M.L.; Vick, J.E. Scaffold design for bone regeneration. J. Nanosci. Nanotechnol. 2014, 14, 15-56. [CrossRef] 
9. Jang, C.; Kim, W.; Kim, G. Effects of fibrous collagen/CDHA/hUCS biocomposites on bone tissue regeneration. Int. J. Biol. Macromol. 2021, 176, 479-489. [CrossRef] [PubMed]

10. Zhao, W.; Huang, Z.; Liu, L.; Wang, W.; Leng, J.; Liu, Y. Porous bone tissue scaffold concept based on shape memory PLA/Fe3O4. Compos. Sci. Technol. 2021, 203, 108563. [CrossRef]

11. Woźniak, M.J.; Chlanda, A.; Oberbek, P.; Heljak, M.; Czarnecka, K.; Janeta, M.; John, Ł. Binary bioactive glass composite scaffolds for bone tissue engineering-Structure and mechanical properties in micro and nano scale. A preliminary study. Micron 2019, 119, 64-71. [CrossRef] [PubMed]

12. Baino, F.; Fiume, E.; Miola, M.; Leone, F.; Onida, B.; Verné, E. Fe-doped bioactive glass-derived scaffolds produced by sol-gel foaming. Mater. Lett. 2019, 235, 207-211. [CrossRef]

13. John, Ł.; Janeta, M.; Rajczakowska, M.; Ejfler, J.; Łydzba, D.; Szafert, S. Synthesis and microstructural properties of the scaffold based on a 3-(trimethoxysilyl)propyl methacrylate-POSS hybrid towards potential tissue engineering applications. RSC Adv. 2016, 6, 66037-66047. [CrossRef]

14. Anitha, A.; Sowmya, S.; Kumar, P.T.S.; Deepthi, S.; Chennazhi, K.P.; Ehrlich, H.; Tsurkan, M.; Jayakumar, R. Chitin and chitosan in selected biomedical applications. Prog. Polym. Sci. 2014, 39, 1644-1667. [CrossRef]

15. Nawrotek, K.; Tylman, M.; Adamus-Włodarczyk, A.; Rudnicka, K.; Gatkowska, J.; Wieczorek, M.; Wach, R. Influence of chitosan average molecular weight on degradation and stability of electrodeposited conduits. Carbohydr. Polym. 2020, $244,116484$. [CrossRef]

16. Huang, Y.M.; Lin, Y.C.; Chen, C.Y.; Hsieh, Y.Y.; Liaw, C.K.; Huang, S.W.; Tsuang, Y.H.; Chen, C.H.; Lin, F.H. Thermosensitive chitosan-gelatin-glycerol phosphate hydrogels as collagenase carrier for tendon-bone healing in a rabbit model. Polymers 2020, 12, 436. [CrossRef]

17. Croisier, F.; Jérôme, C. Chitosan-based biomaterials for tissue engineering. Eur. Polym. J. 2013, 49, 780-792. [CrossRef]

18. Muzzarelli, R.A.A. Chitin Nanostructures in Living Organisms. In Chitin. Topics in Geobiology, 34th ed.; Gupta, N.S., Ed.; Springer: Dordrecht, The Netherlands, 2011. [CrossRef]

19. Pillai, C.K.S.; Paul, W.; Sharma, C.P. Chitin and chitosan polymers: Chemistry, solubility and fiber formation. Prog. Polym. Sci. 2009, 34, 641-678. [CrossRef]

20. Zhou, H.Y.; Jiang, L.J.; Cao, P.P.; Li, J.B.; Chen, X.G. Glycerophosphate-based chitosan thermosensitive hydrogels and their biomedical applications. Carbohydr. Polym. 2015, 117, 524-536. [CrossRef] [PubMed]

21. Palma, P.J.; Ramos, J.C.; Martins, J.B.; Diogenes, A.; Figueiredo, M.H.; Ferreira, P.; Viegas, C.; Santos, J.M. Histologic Evaluation of regenerative endodontic procedures with the use of chitosan scaffolds in immature dog teeth with apical periodontitis. J. Endod. 2017, 43, 1279-1287. [CrossRef]

22. Nawrotek, K.; Tylman, M.; Rudnicka, K.; Balcerzak, J.; Kamiński, K. Chitosan-based hydrogel implants enriched with calcium ions intended for peripheral nervous tissue regeneration. Carbohydr. Polym. 2016, 136, 764-771. [CrossRef] [PubMed]

23. Kong, L.; Gao, Y.; Lu, G.; Gong, Y.; Zhao, N.; Zhang, X. A study on the bioactivity of chitosan/nano-hydroxyapatite composite scaffolds for bone tissue engineering. Eur. Polym. J. 2006, 42, 3171-3179. [CrossRef]

24. Mohamed, K.R.; Beherei, H.H.; El-Rashidy, Z.M. In vitro study of nano-hydroxyapatite/chitosan-gelatin composites for bioapplications. J. Adv. Res. 2014, 5, 201-208. [CrossRef]

25. Chauhan, N.; Singh, Y. L-histidine controls the hydroxyapatite mineralization with plate-like morphology: Effect of concentration and media. Mater. Sci. Eng. C 2021, 120, 111669. [CrossRef]

26. Tredwin, C.J.; Young, A.M.; Georgiou, G.; Shin, S.H.; Kim, H.W.; Knowles, J.C. Hydroxyapatite, fluor-hydroxyapatite and fluorapatite produced via the sol-gel method. Optimisation, characterisation and rheology. Dent. Mater. 2013, 29, 166-173. [CrossRef] [PubMed]

27. Rogina, A.; Ivanković, M.; Ivanković, H. Preparation and characterization of nano-hydroxyapatite within chitosan matrix. Mater. Sci. Eng. C 2013, 33, 4539-4544. [CrossRef]

28. Hu, Q.; Li, B.; Wang, M.; Shen, J. Preparation and characterization of biodegradable chitosan/hydroxyapatite nanocomposite rods via in situ hybridization: A potential material as internal fixation of bone fracture. Biomaterials 2004, 25, 779-785. [CrossRef]

29. Dong, Y.; Liang, J.; Cui, Y.; Xu, S.; Zhao, N. Fabrication of novel bioactive hydroxyapatite-chitosan-silica hybrid scaffolds: Combined the sol-gel method with 3D plotting technique. Carbohydr. Polym. 2018, 197, 183-193. [CrossRef]

30. Lai, S.M.; Chen, W.C.; Wu, T.W.; Yang, A.J.M.; Yang, C.H. Properties and preparation of chitosan/silanol quaternary ammonium modified silica hybrids using sol-gel process. J. Macromol. Sci. Part B Phys. 2011, 50, 1430-1446. [CrossRef]

31. Pipattanawarothai, A.; Suksai, C.; Srisook, K.; Trakulsujaritchok, T. Non-cytotoxic hybrid bioscaffolds of chitosan-silica: Sol-gel synthesis, characterization and proposed application. Carbohydr. Polym. 2017, 178, 190-199. [CrossRef]

32. Kaliaraj, R.; Gandhi, S.; Sundaramurthi, D.; Sethuraman, S.; Krishnan, U.M. A biomimetic mesoporous silica-polymer composite scaffold for bone tissue engineering. J. Porous Mater. 2018, 25, 397-406. [CrossRef]

33. Beck, G.R.; Ha, S.W.; Camalier, C.E.; Yamaguchi, M.; Li, Y.; Lee, J.K.; Weitzmann, M.N. Bioactive silica-based nanoparticles stimulate bone-forming osteoblasts, suppress bone-resorbing osteoclasts, and enhance bone mineral density in vivo. Nanomed. Nanotechnol. Biol. Med. 2012, 8, 793-803. [CrossRef]

34. Douglas, T.E.L.; Skwarczynska, A.; Modrzejewska, Z.; Balcaen, L.; Schaubroeck, D.; Lycke, S.; Vanhaecke, F.; Vandenabeele, P.; Dubruel, P.; Jansen, J.A.; et al. Acceleration of gelation and promotion of mineralization of chitosan hydrogels by alkaline phosphatase. Int. J. Biol. Macromol. 2013, 56, 122-132. [CrossRef] 
35. Adamski, R.; Siuta, D.; Kukfisz, B.; Mitkowski, P.T.; Szaferski, W. Influence of process parameters in superheated steam drying on fire and explosion parameters of woody biomass. Fuel Process. Technol. 2021, 211, 106597. [CrossRef]

36. Pakowski, Z.; Krupinska, B.; Adamski, R. Prediction of sorption equilibrium both in air and superheated steam drying of energetic variety of willow Salix viminalis in a wide temperature range. Fuel 2007, 86, 1749-1757. [CrossRef]

37. Sowjanya, J.A.; Singh, J.; Mohita, T.; Sarvanan, S.; Moorthi, A.; Srinivasan, N.; Selvamurugan, N. Biocomposite scaffolds containing chitosan/alginate/nano-silica for bone tissue engineering. Colloids Surfaces B Biointerfaces 2013, 109, 294-300. [CrossRef] 